\title{
25-Vitamin D levels in chronic hepatitis C infection: association with cirrhosis and sustained virologic response
}

\author{
David Backstedt, Mark Pedersen, Myunghan Choi, Anil Seetharam
}

University of Arizona College of Medicine Phoenix, Banner University Liver Disease Center, Banner University Medical Center, USA

Abstract

Background Low serum 25-Vitamin D levels are associated with advanced fibrosis in hepatitis C infection. Vitamin D supplementation has been hypothesized to augment response rates to interferon-based therapy. To date, no investigation has evaluated vitamin D levels during directacting antiviral therapy. We aimed to evaluate the prevalence of vitamin D deficiency in cirrhotic and non-cirrhotic cohorts, the predictive value of pretreatment levels for a sustained virologic response, and the changes in $25-\mathrm{OH}$ vitamin $\mathrm{D}$ levels during direct-acting antiviral therapy.

Methods Two hundred eighteen patients with chronic hepatitis $\mathrm{C}$ who completed directacting antiviral therapy were consecutively enrolled. Vitamin D levels were measured using chemiluminescence immunoassay, prior to initiation and at completion of therapy. Advanced liver fibrosis (cirrhosis) was determined by biopsy, FibroSURE blood test, or imaging.

Results A sustained virologic response was achieved in $79 \%(n=172)$ of patients, with $19 \%(n=44)$ relapsing. A total of 123 (56.4\%) patients were cirrhotic. The prevalence of Vitamin D deficiency $(10-20 \mathrm{ng} / \mathrm{mL})$ and severe deficiency $(<10 \mathrm{ng} / \mathrm{mL})$ was significantly higher in cirrhotic patients $(\mathrm{P}=0.04)$. Pre-treatment vitamin $\mathrm{D}$ levels in cirrhotic patients were negatively correlated with Model for End-Stage Liver Disease score, total bilirubin and INR $(\mathrm{P}<0.05)$. Neither pretreatment vitamin $\mathrm{D}$ level nor the change during therapy was associated with an increased rate of sustained virologic response.

Conclusions The prevalence of vitamin D deficiency is higher in hepatitis-C-related cirrhotic cohorts compared to non-cirrhotic patients and correlates with components of hepatic function. Neither pretreatment vitamin D level nor the change during therapy was associated with an increased rate of sustained virologic response.

Keywords Hepatitis C, vitamin D, 25-OH vitamin D, sustained virologic response, direct acting antiviral

Ann Gastroenterol 2017; 30 (1): 1-5

\section{Introduction}

Vitamin $\mathrm{D}$ is an essential hormone for calcium homeostasis [1]; endogenous vitamin D (from skin exposure to ultraviolet $\mathrm{B}$ radiation) or ingested vitamin $\mathrm{D}$ is converted

Banner University Liver Disease Center, University of Arizona College of Medicine Phoenix

Conflict of Interest: Dr. Seetharam reports speaking for Gilead and Janssen

Correspondence to: Anil Seetharam M.D., 1300 N. $12^{\text {th }}$ Street Suite 404, Phoenix, AZ 85006, USA,

e-mail: Anil.Seetharam@bannerhealth.com

Received 10 July 2016; accepted 03 December 2016; published online 5 January 2017

DOI: https://doi.org/10.20524/aog.2017.0120 to 25-hydroxyvitamin $\mathrm{D}$ by hepatic microsomal vitamin $\mathrm{D}$ hydroxylases. The majority of 25 -hydroxyvitamin $\mathrm{D}$ is subsequently converted to its active form, calcitriol, 1,25 $(\mathrm{OH})_{2} \mathrm{D}$, in the kidney and to a lesser extent in various other tissues, including the liver, adipose tissue, macrophages, and dendritic cells $[2,3]$. Owing to its relatively long half-life (2-3 weeks), 25-hydroxyvitamin D level is the best measure of storage; however, there is no clear consensus regarding optimal vitamin D level [1,3-5]. The Endocrine Society Clinical Practice Guidelines currently define serum levels $<30 \mathrm{ng} / \mathrm{mL}$ as insufficiency and levels $<20 \mathrm{ng} / \mathrm{mL}$ as deficiency [4].

Recently, there has been significant interest in the association of serum 25-vitamin D levels and supplementation during the natural history and treatment of chronic hepatitis $\mathrm{C}$ virus $(\mathrm{HCV})$ infection [6,7]. In vitro, vitamin $\mathrm{D}$ increases the expression of interferon-stimulated genes (ISGs), which augment innate and adaptive immune responses against 
$\mathrm{HCV}$ [8]. Further in vitro investigation has identified a synergistic effect of calcitriol supplementation with interferonalpha to suppress HCV viral replication in Huh-7.5 cells [9]. In addition, calcitriol may play a role in viral suppression independent of vitamin D receptor activation [10].

Previous investigations have identified an inverse relation between serum vitamin D level and stage of fibrosis [11-13]. In a recent meta-analysis, vitamin $\mathrm{D}$ levels of $<10 \mathrm{ng} / \mathrm{mL}$ and $<30 \mathrm{ng} / \mathrm{mL}$ were associated with significant odds of advanced fibrosis [12]. Additionally, an investigation in an Asian cohort of HCV and HCV/HIV coinfection found vitamin $\mathrm{D}$ deficiency to be an independent predictor for advanced fibrosis [13].

Although the correlation between low vitamin D status and advanced fibrosis stage is often corroborated, the issue is controversial and consensus on pretreatment levels and their influence on a sustained virologic response (SVR) to antiviral therapy has proved elusive [11-12,14,15]. A study by Kitson et al evaluated 274 patients with hepatitis $C$ genotype 1 undergoing treatment with pegylated (peg)-interferon plus ribavirin for up to 48 weeks and found that subjects who failed to achieve SVR had lower mean pretreatment vitamin D levels (30.7 vs. $33.9 \mathrm{ng} / \mathrm{mL} ; \mathrm{P}=0.03$ ) and a greater prevalence of vitamin D levels $<30 \mathrm{ng} / \mathrm{mL}$ ( $53 \%$ vs. $40 \%$; $\mathrm{P}=0.03$ ). However, on multivariate analysis no significant association was found between vitamin D levels and SVR [15]. In a follow up meta-analysis, no significant association between baseline 25(OH) D levels and SVR existed in patients treated with peginterferon plus ribavirin [16]. In contrast to the above reports, a meta-analysis by Garcia-Alvarez found (when outliers were excluded) that low vitamin D levels were associated with lower odds of achieving SVR [12].

Previous studies have evaluated associations of vitamin D and treatment outcomes in the context of interferon-based therapy. To date, no investigation has evaluated the influence of vitamin D levels on SVR with direct-acting antiviral (DAA) therapy. The purpose of this study was to evaluate the association of vitamin D levels with cirrhosis in an HCV-infected cohort and to assess the predictive value of pretreatment serum 25-vitamin D level for achieving SVR12, defined as viral load undetectable or below the level of detection 12 weeks post therapy. Secondary objectives included evaluating the change in serum 25-vitamin D levels during DAA therapy and determining if the change in levels was predictive of SVR.

\section{Patients and methods}

\section{HCV treatment population}

After protocol approval by the institution's Review Board, 218 patients with chronic hepatitis $\mathrm{C}$ who completed DAA therapy between January 2013 and December 2015 were consecutively enrolled. Subjects received one of the following regimens, in accordance with AASLD/IDSA guidelines at the time of enrollment [17]: 1) pegylated interferon alfa $2 \mathrm{a}$ $(\mathrm{IFN})+$ sofosbuvir $(\mathrm{SOF})+$ ribavirin $(\mathrm{RBV}) ; 2) \mathrm{SOF}+\mathrm{RBV}$;
3) SOF + simeprevir (SMV); 4) ledipasvir (LDV) + SOF; and 5) $\mathrm{LDV}+\mathrm{SOF}+\mathrm{RBV}$. Patients already receiving vitamin $\mathrm{D}$ supplementation or who were prescribed vitamin D during antiviral therapy were excluded from analysis.

Regimens utilizing RBV were weight-based, with initial dosing of $1000 \mathrm{mg}$ daily in patients weighing $<75 \mathrm{~kg}$ and $1200 \mathrm{mg}$ daily in those weighing $\geq 75 \mathrm{~kg}$ and dose reductions allowed at the physician's discretion. End of treatment response (ETR) was defined as a viral load undetectable or below the level of detection at the completion of the regimen. SVR12 was defined as a viral load undetectable or below the level of detection 12 weeks post therapy.

\section{Vitamin D measurement and clinical characteristics}

25-hydroxyvitamin D levels were assessed prior to the start of therapy and at ETR with chemiluminescence immunoassay; concentrations were recorded in $\mathrm{ng} / \mathrm{mL}$. The following operational definitions for baseline vitamin D levels were employed: severe deficiency, vitamin D level $<10 \mathrm{ng} / \mathrm{mL}$; deficiency, $\geq 10 \mathrm{ng} / \mathrm{mL}$ and $<20 \mathrm{ng} / \mathrm{mL}$; and insufficiency, $\geq 20 \mathrm{ng} / \mathrm{mL}$ and $<30 \mathrm{ng} / \mathrm{mL}$. Advanced liver fibrosis (cirrhosis) was determined using one or more of the following methods: liver biopsy, elastography, FibroTest (BioPredictive ${ }^{\varpi}$ ), or crosssectional imaging consistent with cirrhosis. Demographic characteristics were assessed prior to the initiation of treatment and included age, sex, ethnicity, previous treatment history/ outcome, genotype, and viral load.

\section{Statistical analysis}

Descriptive statistics, including frequencies, chi-square and t-tests, were used for the baseline demographics and the association of vitamin D with fibrosis. Pearson correlation coefficients were used to determine the magnitude and direction of the relationship between pretreatment vitamin D and other markers of liver disease. Sequential data points were analyzed with repeated measures ANOVA to evaluate significant changes between time points controlling for covariates including age, sex, and body mass index. To determine whether pretreatment vitamin $\mathrm{D}$ levels or changes in the levels were predictive of SVR12, binary logistic regression was conducted, controlling for age, sex, and body mass index. The significance level was set as a P-value of 0.05 . SPSS Statistics software (Version 22) was used for the statistical analyses.

\section{Results}

\section{Baseline demographics}

Two hundred eighteen patients completed therapy with DAA (Table 1). The mean age of the population was $56 \pm 10.4$ years old and $65 \%$ were male. Genotype 1 predominated $(n=134$, 
$61.5 \%)$ followed by genotype $2(n=53,24.3 \%)$, genotype 3 $(\mathrm{n}=26,11.9 \%)$, and genotype $4(\mathrm{n}=5,2.3 \%)$. Patients were predominately Caucasian ( $\mathrm{n}=143,65.6 \%)$, followed by Hispanic $(n=48,22 \%)$ and African American $(n=12,5.5 \%)$. A total of 117 (53.7\%) patients were treated with SOF and RBV, 37 (17.0\%) with INF, SOF, and RBV, 51 (23.4\%) with SMV and SOF, 11 (5.0\%) with LDV and SOF (Harvoni), and 2 (0.9\%) with LDV, SOF and RBV. A total of 95 patients (43.6\%) were noncirrhotic; of these, 25 (11.4\%) had stage 1 fibrosis, 29 (13.3\%) stage 2 , and $41(18.8 \%)$ stage 3 . One hundred twenty-three (56.4\%) patients were cirrhotic, with an average MELD score of 9.6. One hundred thirty-nine (64\%) were treatment-naïve and $79(36 \%)$ were interferon-experienced. Of those with previous interferon exposure, 57 (26\%) were non-responders and $22(10 \%)$ were relapsers. Ninety-eight percent of the population $(n=213)$ achieved ETR. Seventy-nine percent of the population $(n=172)$ achieved SVR with $19 \%(n=44)$ of patients relapsing. SVR rates were $71 \%$ in cirrhotic patients versus $96 \%$ in non-cirrhotic.

\section{Pretreatment vitamin D levels and cirrhosis}

Overall, $43 \%$ ( $n=93$ ) of subjects were found to have vitamin $\mathrm{D}$ deficiency (vitamin $\mathrm{D}<20 \mathrm{ng} / \mathrm{mL})$ and $33 \%(\mathrm{n}=72)$ were found to have insufficiency (vitamin D $20-30 \mathrm{ng} / \mathrm{mL}$ ). There was no significant difference in pretreatment mean level of vitamin $\mathrm{D}$ in patients with and without cirrhosis (23.6 \pm 16.7 versus $27.2 \pm 14.8 \mathrm{ng} / \mathrm{mL})$. However, more cirrhotic patients than noncirrhotic patients had vitamin D deficiency $(\geq 10 \mathrm{ng} / \mathrm{mL}$ and $<20 \mathrm{ng} / \mathrm{mL})(\mathrm{P}=0.04)$. The same was true for severe vitamin $\mathrm{D}$ deficiency $(<10 \mathrm{ng} / \mathrm{mL})(\mathrm{P}=0.04)$. Vitamin $\mathrm{D}$ insufficiency $(\geq 20 \mathrm{ng} / \mathrm{mL}$ and $<30 \mathrm{ng} / \mathrm{mL}$ ) was seen in similar numbers of both cirrhotic and non-cirrhotic patients (Table 2).

Pre-treatment vitamin D levels in the cirrhotic population were also found to have a negative correlation with Model for End-Stage Liver Disease (MELD) score ( $r=-0.240$, $\mathrm{P}<0.01)$, total bilirubin $(\mathrm{r}=-0.263, \mathrm{P}<0.01)$, and international normalized ratio (INR) $(\mathrm{r}=-0.214, \mathrm{P}<0.05)$, demonstrating that cirrhotic patients with higher pretreatment vitamin $\mathrm{D}$ levels were more likely to have lower MELD scores, total bilirubin level, and INR.

\section{Vitamin D levels at baseline and ETR and response to therapy}

A pretreatment vitamin D level $>20 \mathrm{ng} / \mathrm{mL}$ was not associated with a higher SVR12 rate: 76\% (71/93) of patients with vitamin D levels $<20 \mathrm{ng} / \mathrm{mL}$ achieved SVR versus $81 \%$ $(101 / 125)$ with vitamin D level $>20 \mathrm{ng} / \mathrm{mL}$. Severe vitamin D deficiency and vitamin D insufficiency were also not associated with significant differences in SVR. Similarly, neither pretreatment and end of treatment vitamin D levels nor the change in level were predictive of SVR12 in either cirrhotic or non-cirrhotic patients. ETR vitamin D levels did not change significantly in either the cirrhotic or the non-cirrhotic
Table 1 Baseline demographic characteristics

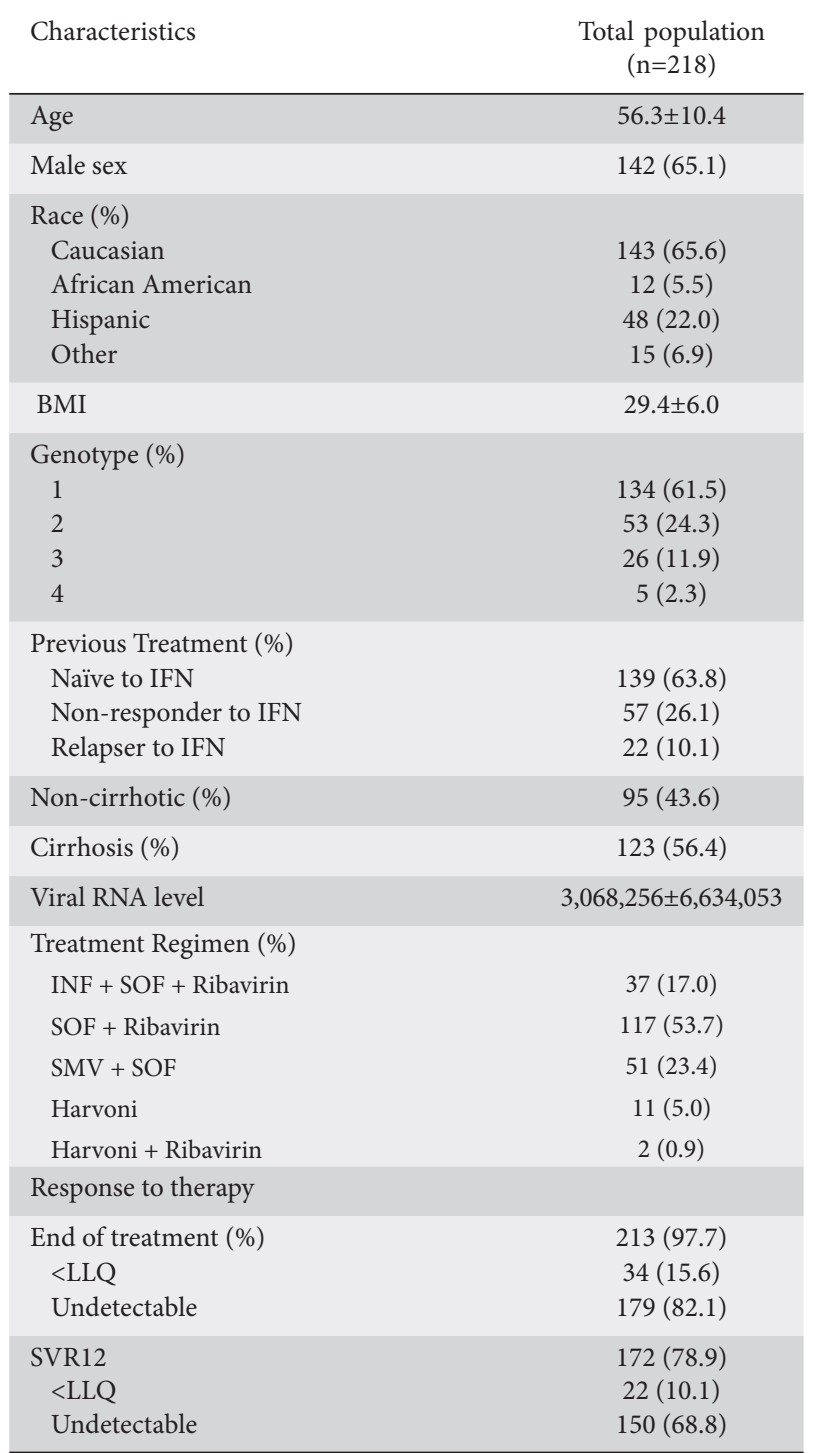

Values are mean $\pm S D$ or $n(\%)$.

$B M I$, body mass index; INF, pegylated interferon alfa $2 a$; $L L Q$, lower limit of quantification; SOF, sofosbuvir; SMV, simeprevir; SVR12, viral load undetectable or below the level of detection 12 weeks post therapy

Table 2 Association of vitamin D with cirrhosis

\begin{tabular}{llll}
\hline Vitamin D & Cirrhotic & Non-cirrhotic & P-value \\
\hline $\begin{array}{l}\text { Pre-treatment vitamin } \\
\text { D level }(\mathrm{ng} / \mathrm{mL})\end{array}$ & $23.6 \pm 16.7$ & $27.2 \pm 14.8$ & 0.09 \\
\hline $\begin{array}{l}\text { Insufficiency }(\mathrm{n}=72) \\
\text { Deficiency }(\mathrm{n}=81)\end{array}$ & $37(51 \%)$ & $35(49 \%)$ & 0.29 \\
$\begin{array}{l}\text { Severe deficiency } \\
(\mathrm{n}=12)\end{array}$ & $93(65 \%)$ & $28(35 \%)$ & 0.04 \\
\hline $\begin{array}{l}\text { Insufficiency }<30 \mathrm{ng} / \mathrm{mL}), \text { deficiency }(<20 \mathrm{ng} / \mathrm{mL}), \text { severe deficiency }(<10 \mathrm{ng} / \mathrm{mL}) \\
\end{array}$
\end{tabular}

population. Similarly, the change in vitamin D levels during treatment was not significant in subjects achieving SVR12, or in patients who failed DAA therapy (Table 3). 


\section{Discussion}

Vitamin D and associated metabolites are known to have pleiotropic effects beyond calcium homeostasis [1-3,18]. There is considerable interest in evaluating the influence of vitamin D deficiency and supplementation on the course and treatment of chronic liver diseases. Vitamin D has been shown to influence the expression of interferon-stimulated genes [8] and to suppress HCV viral replication [10]. Additionally, emerging data indicate that vitamin $\mathrm{D}$ deficiency is associated with advanced degrees of fibrosis in chronic HCV infection and that this association may be more pronounced depending on ethnicity [19]. Racial differences in vitamin D physiology or race-specific factors may modify immune responses during the course of chronic HCV infection [20]. Additionally, other factors that may influence the interplay between vitamin $\mathrm{D}$ and a sustained virologic response include polymorphisms in vitamin D binding protein [2], interleukin 28B polymorphisms, degree of fibrosis, genotype, and dyslipidemia [21].

Controversy exists regarding the utility of vitamin $\mathrm{D}$ levels and their supplementation in conjunction with antiviral therapy to augment a sustained virologic response to therapy $[11,12,14-16]$. Previous investigations have evaluated the role of vitamin $\mathrm{D}$ with interferon-based therapies, but no such studies have evaluated its utility in conjunction with DAA therapy.

Similar to previously reported data [3], we found a high prevalence $(43 \%)$ of vitamin D deficiency $(<20 \mathrm{ng} / \mathrm{mL})$ in the chronically infected cohort; with significantly higher rates in the cirrhotic subpopulation compared to subjects with lower stages of fibrosis. In addition, correlation analysis in the cirrhotic cohort identified significant inverse associations of vitamin D level with serum INR, total bilirubin, and MELD score.

To our knowledge, this is the first examination of vitamin D levels during the course of DAA therapy. With DAA treatment, vitamin $\mathrm{D}$ levels modestly increased in all populations but the change was not significant (Table 3). In addition, neither the pretreatment level nor the change in levels during DAA therapy was associated with SVR12. DAA therapy represents a targeted therapeutic approach, unlike peg-interferon and ribavirin; hence, any beneficial pleiotropic effect of vitamin D

Table 3 Changes in vitamin D levels with direct-acting antiviral therapy

\begin{tabular}{lccc}
\hline Patients & $\begin{array}{c}\text { Pre-treatment } \\
\text { vit D level }\end{array}$ & $\begin{array}{c}\text { End of } \\
\text { treatment } \\
\text { vit D level }\end{array}$ & P-value \\
\hline All & $25.3 \pm 15.9$ & $26.4 \pm 12.5$ & 0.10 \\
Cirrhotic & $23.6 \pm 16.7$ & $25.1 \pm 12.6$ & 0.15 \\
Non-cirrhotic & $27.2 \pm 14.8$ & $28.1 \pm 12.2$ & 0.40 \\
\hline Patients achieving SVR12 & $25.7 \pm 16.5$ & $26.7 \pm 12.9$ & 0.21 \\
\hline Patients not achieving SVR12 & $23.5 \pm 13.8$ & $25.1 \pm 10.6$ & 0.15 \\
\hline $\begin{array}{l}\text { SVR12, viral load undetectable or below the level of detection 12 weeks post } \\
\text { therapy }\end{array}$ & & \\
\hline
\end{tabular}

sufficiency on innate/adaptive immune responses may be obviated. Although vitamin D levels may no longer influence SVR with improved therapeutic agents, further studies are needed to determine optimal levels in patients with cirrhosis, as supplementation may still be of benefit given its pleiotropic effects on calcium homeostasis, the cardiovascular system, diabetes, and autoimmune diseases $[1,2]$.

It should be noted that 25-hydroxyvitamin D levels were relatively higher in our population compared with a previous meta-analysis [12]. A limitation of this investigation is that it was performed at a single center, in an environment with high levels of ambient sunlight exposure. Furthermore, a commercially available chemiluminescence assay was used to measure $25-\mathrm{OH}$ vitamin D levels. Such assays have increased variation and higher bias compared to other modalities, such as liquid chromatography or tandem mass spectrometry [24]. Finally, the changes in vitamin D levels were measured at ETR; longitudinal analysis over a relatively short timeframe (often 3 months with direct acting antiviral regimens) may not allow sufficient time to see a demonstrable improvement in vitamin D levels and global hepatic function. Ongoing, prospective assessments at SVR and beyond would be necessary to draw firmer conclusions.

Further prospective investigation is needed to compare varied geographic latitudes and to evaluate differences among minority populations. In addition, for the regimens employed, our reported SVR12 rate for the cohort is lower than that in published phase II/III clinical studies [22,23]. The investigation represents experience with second-generation DAA therapy.

\section{Summary Box}

\section{What is already known:}

- Vitamin D deficiency and insufficiency are common in cirrhotic populations with hepatitis $\mathrm{C}$ (HCV)

- Vitamin D augments innate and adaptive immune defenses against HCV and supplementation may augment sustained virologic response rates to interferon-based therapy

- New therapeutic antivirals against HCV are direct acting and do not rely on immune responses for viral clearance

\section{What the new findings are:}

- Vitamin D levels do not significantly change during the course of direct-acting antiviral therapy

- Neither pretreatment serum 25-vitamin D levels nor the change in level is predictive of the response to direct-acting antiviral therapy

- Significant inverse correlations exist between 25-vitamin D level and the degree of cholestasis/ global hepatic function 
With the advent of newer and increasingly efficacious regimens we would anticipate increased SVR12 rates in clinical practice, further lessening the role for vitamin D supplementation specifically for the purposes of augmenting response rates.

\section{References}

1. Holick MF. Vitamin D deficiency. N Engl J Med 2007;357:266-281.

2. Rahman $\mathrm{AH}$, Branch $\mathrm{AD}$. Vitamin $\mathrm{D}$ for your patients with chronic hepatitis C? J Hepatol 2013;58:184-189.

3. Iruzubieta P, Terán, Crespo J, Fábrega E. Vitamin D deficiency in chronic liver disease. World J Hepatol 2014;6:901-915.

4. Holick MF, Binkley NC, Bischoff-Ferrari HA, et al; Endocrine Society. Evaluation, treatment, and prevention of vitamin D deficiency: an Endocrine Society clinical practice guideline. J Clin Endocrinol Metab 2011;96:1911-1930.

5. Ross AC, Manson JE, Abrams SA, et al. The 2011 report on dietary reference intakes for calcium and vitamin D from the Institute of Medicine: what clinicians need to know. J Clin Endocrinol Metab 2011;96:53-58.

6. Abu-Mouch S, Fireman Z, Jarchovsky J, Zeina AR, Assy N. Vitamin D supplementation improves sustained virologic response in chronic hepatitis C (genotype 1)-naïve patients. World $J$ Gastroenterol 2011;17:5184-5190.

7. Bitetto D, Fabris C, Fornasiere E, et al. Vitamin D supplementation improves response to antiviral treatment for recurrent hepatitis $\mathrm{C}$. Transpl Int 2011;24:43-50.

8. Gal-Tanamy M, Bachmetov L, Ravid A, et al. Vitamin D: an innate antiviral agent suppressing hepatitis $\mathrm{C}$ virus in human hepatocytes. Hepatology 2011;54:1570-1579.

9. Lange CM, Gouttenoire J, Duong FH, Morikawa K, Heim MH, Moradpour D. Vitamin D receptor and Jak-STAT signaling crosstalk results in calcitriol-mediated increase of hepatocellular response to IFN- $\alpha$. J Immunol 2014;192:6037-6044.

10. Matsumura T, Kato T, Sugiyama N, et al. 25-Hydroxyvitamin D3 suppresses hepatitis C virus production. Hepatology 2012;56:1231-1239.

11. Petta $\mathrm{S}$, Cammà $\mathrm{C}$, Scazzone $\mathrm{C}$, et al. Low vitamin $\mathrm{D}$ serum level is related to severe fibrosis and low responsiveness to interferonbased therapy in genotype 1 chronic hepatitis C. Hepatology 2010;51:1158-1167.

12. García-Álvarez M, Pineda-Tenor D, Jiménez-Sousa MA, Fernández-Rodríguez A, Guzmán-Fulgencio $\mathrm{M}$, Resino $\mathrm{S}$. Relationship of vitamin D status with advanced liver fibrosis and response to hepatitis $\mathrm{C}$ virus therapy: a meta-analysis. Hepatology 2014;60:1541-1550.

13. Avihingsanon A, Jitmitraparp S, Tangkijvanich $\mathrm{P}$, et al; HIVNAT125 study team. Advanced liver fibrosis by transient elastography, fibrosis 4 , and alanine aminotransferase/platelet ratio index among Asian hepatitis $\mathrm{C}$ with and without human immunodeficiency virus infection: role of vitamin D levels. J Gastroenterol Hepatol 2014;29:1706-1714.

14. Villar LM, Del Campo JA, Ranchal I, Lampe E, Romero-Gomez M. Association between vitamin $\mathrm{D}$ and hepatitis $\mathrm{C}$ virus infection: a meta-analysis. World J Gastroenterol 2013;19:5917-5924.

15. Kitson MT, Dore GJ, George J, et al. Vitamin D status does not predict sustained virologic response or fibrosis stage in chronic hepatitis C genotype 1 infection. J Hepatol 2013;58:467-472.

16. Kitson MT, Sarrazin C, Toniutto P, Eslick GD, Roberts SK. Vitamin $\mathrm{D}$ level and sustained virologic response to interferon-based antiviral therapy in chronic hepatitis $\mathrm{C}$ : a systematic review and meta-analysis. J Hepatol 2014;61:1247-1252.

17. AASLD/IDSA HCV Guidance Panel. Hepatitis C guidance: AASLD-IDSA recommendations for testing, managing, and treating adults infected with hepatitis C virus. Hepatology 2015;62:932-954.

18. Gutierrez JA, Parikh N, Branch AD. Classical and emerging roles of vitamin D in hepatitis C virus infection. Semin Liver Dis 2011;31:387-398.

19. White DL, Tavakoli-Tabasi S, Kanwal F, et al. The association between serological and dietary vitamin $\mathrm{D}$ levels and hepatitis C-related liver disease risk differs in African American and white males. Aliment Pharmacol Ther 2013;38:28-37.

20. Weintraub SJ, Fleckenstein JF, Marion TN, Madey MA, Mahmoudi TM, Schechtman KB. Vitamin D and the racial difference in the genotype 1 chronic hepatitis $C$ treatment response. Am J Clin Nutr 2012;96:1025-1031.

21. Cavalcante LN, Lyra AC. Predictive factors associated with hepatitis C antiviral therapy response. World J Hepatol 2015;7:1617-1631.

22. Kowdley KV, Lawitz E, Crespo I, et al. Sofosbuvir with pegylated interferon alfa-2a and ribavirin for treatment-naive patients with hepatitis C genotype-1 infection (ATOMIC): an open-label, randomised, multicentre phase 2 trial. Lancet 2013;381:2100-2107.

23. Lawitz E, Sulkowski MS, Ghalib R, et al. Simeprevir plus sofosbuvir, with or without ribavirin, to treat chronic infection with hepatitis $\mathrm{C}$ virus genotype 1 in non-responders to pegylated interferon and ribavirin and treatment-naive patients: the COSMOS randomised study. Lancet 2014;384:1756-1765.

24. Enko D, Kriegshäuser G, Stolba R, Worf E, Halwachs-Baumann G. Method evaluation study of a new generation of vitamin D assays. Biochem Med (Zagreb) 2015;25:203-212. 